\section{Budd-Chiari Syndrome after Taking Oral Contraceptives}

Brit. med.f., 1967, 4, 660

Budd (1846) reported a case of hepatic vein thrombosis caused by an abscess of the liver. Subsequently Chiari (1899) described three and reviewed 10 cases. Parker (1959) was able to find 149 cases described in the literature and contributed a further 18 cases. The syndrome seems to be more common in men than in women, and the average age at necropsy is 34 years. The possibility of an increased risk of thromboembolic disorders in patients taking oral contraceptives has been discussed lately. A number of case reports of thrombophlebitis and pulmonary embolism have been published, and the Medical Research Council (1967) has examined the question. Only one case of hepatic vein thrombosis in a young woman on oral contraceptive has been reported (Ecker et al., 1966). The patient had been on norethisterone and mestranol (Norinyl) for 14 days when her symptoms started.

We have seen the Budd-Chiari syndrome in a previously healthy woman taking an oral contraceptive. Because of the possible causal relationship we consider the case worth reporting.

A 28-years-old housewife was admitted to hospital on 20 December 1966. Previous health had been excellent. For contraception she had periodically taken lynoestrenol plus mestranol (Lyndiol) during 12 to 18 months. The treatment was withdrawn on 12 December 1966 because of nausea. She had been taking no other drugs. During the last month before admission to hospital she had gradually increasing abdominal distension, epigastric pains, loss of appetite, and nausea. No jaundice or discoloration of faeces or urine were noted

On admission her general condition was fairly good ; no signs of anaemia or jaundice; no spider naevi or palmar erythema; abdomen grossly distended, with dilated abdominal veins; the liver was felt 8-10 $\mathrm{cm}$. below the right rib margin, smooth, not tender; the spleen was enlarged; ascites present; on the side of the neck were several small lymph nodes.

Laboratory investigations showed: Haemoglobin, 14.7 g./100 ml. Erythrocyte sedimentation rate $7 \mathrm{~mm}$. Leucocytes, 6,520/ cu. mm., normal distribution. Alkaline phosphatase, 12.1 KingArmstrong units. S.G.O.T., 1.1. Thymol turbidity test, 0.07 .
Prothrombin, $71 \%$. Bromsulphalein retention, $2 \%$. Creatinine, $1.0 \mathrm{mg} . / 100 \mathrm{ml}$. Benzidine reaction on faeces negative. Urine: no albumin, no sugar. Electrophoresis: albumin, $3.1 \%$; gammaglobulin, $0.78 \%$. Sigmoidoscopy, normal, no piles. Gynaecological examination normal.

$X$-ray examinations showed only raised diaphragm.

Needle liver biopsy (9 January 1967): liver tissue with acute congestion and fibrosis, presumably cirrhosis. Splenoportography (20 January) partly unsuccessful ; rather large accumulation of contrast medium at the site of the spleen; faint filling of the normally formed vena lienalis. Microscopical evaluation of spleen puncture: relative lymphocytosis, otherwise no pathological changes.

The general condition of the patient deteriorated. Oedema of the legs developed and the ascites increased. Despite treatment she died on 14 March after repeated haemorrhages.

Necropsy.-Liver: 30 by 18 by $8.5 \mathrm{~cm}$. ; weight $3,330 \mathrm{~g}$. Surface nodular consistency compact. Colour of surface varied from dark red to light bronze. In the right lobe were several $1-$ to $2-\mathrm{cm}$. yellow, soft necroses. Large confluent areas of the parenchyma showed haemorrhagic infarcts. Histological examination showed endophlebitis obliterans. A small hepatic vein showed thrombosis besides infarcts and some cirrhotic changes. Vena cava inferior: no thrombosis; all venae hepaticae were occluded at the junction with vena cava; in the liver a small thrombus in a larger hepatic vein.

Oesophagus: large contorted veins; $10 \mathrm{~cm}$. from cardia a thrombosed vein in the wall.

Spleen: 16 by 10 by $6 \mathrm{~cm}$. ; weight $440 \mathrm{~g}$.; congested.

Prospective studies running over a sufficiently long period are urgently needed to evaluate the risk of oral contraceptives.

We owe thanks to Dr. Ole Werdelin, University Clinic, Department of Pathology, for the necropsy report.

KIRSTEN STERUP, M.D. JOHANNES MOSBECH, M.D.

\section{St. Elisabeth's Hospital \\ Department of Medicine, Copenhagen, Denmark}

\section{RRPERENCES}

Budd, G. (1846). Diseases of the Liver, p. 151. Philadelphia.

Chiari, H. (1899). Beitr. path. Anat., 26, 1.

Ecker, J. A., McKittrick, J. E., and Failing, R. M. (1966). Amer. 3. Gastroent., 45, 429.

Medical Research Council (1967). Brit. med. 7., 2, 355.

Parker, R. G. F. (1959). Medicine (Baltimore), 38, 369.

\section{Epilepsy and Liver Dysfunction in Association with Hypernephroma}

Brit. med. F., 1967, 4, 660-661

Mohamed (1965b) reported the case of a patient with a hypernephroma who died after a protracted illness associated with fever, anaemia, loss of weight, progressive hepatosplenomegaly, and, preterminally, episodes of grand mal epilepsy. At necropsy there was no evidence of metastatic spread, and Mohamed suggested that the epileptiform seizures and the liver-cell dysfunction would have resolved if the renal tumour had been resected during life. The present report would seem to support this prediction.

\section{CAse Report}

A 69-year-old man was admitted to hospital at the end of August 1965 because of drop attacks. He gave no history of loss of consciousness, vertigo, injury, or incontinence in association with these episodes. For three months before admission he had been unwell, anarexic, and losing weight. $\mathrm{He}$ also complained of a feeling of weakness in his legs, a tremor of his hands, frontal headaches, and nocturia.
On examination he was cachectic, pale, and apathetic. There was generalized muscle-wasting with fasciculation, and muscle power was diminished. Reflexes were present and equal, and the plantar responses were flexor. Some impairment of sensation in both feet and incoordination of movement of the left leg were found. Pulse rate was 48 and regular. Blood pressure was 140/80. There were no signs of cardiac failure. The liver edge extended three fingerbreadths below the costal margin and was firm and regular. Splenomegaly was not detected. Initially the patient was apyrexic, but later he developed an intermittent pyrexia, his temperature being as high as $101^{\circ} \mathrm{F} .\left(38.3^{\circ} \mathrm{C}\right.$.) on several occasions.

Investigations. - Erythrocyte sedimentation rate was $134 \mathrm{~mm}$. in first hour (Westergren). Haemoglobin was 7.7 g. $/ 100 \mathrm{ml}$., the red cells being hypochromic and microcytic. The reticulocytes were $1.4 / 100$ red cells. The white cell count was $6,000 / \mathrm{cu}$. $\mathrm{mm}$. Examination of the sternal marrow showed evidence of active normoblastic erythropoiesis with occasional macronormoblasts. There was no excess of megakaryocytes or plasma cells. Iron storage appeared to be abundant. Plasma urea, electrolytes, bilirubin, aspartate aminotransferase, and alanine aminotransferase were all normal. The plasma alkaline phosphatase was raised to 33 K.A. units $/ 100 \mathrm{ml}$., and the bromsulphalein test was abnormal, there being $35 \%$ retention at 25 minutes and $28 \%$ at 45 minutes. The prothrombin time was 17 seconds (control 15 seconds). The plasma albumin/globulin ratio was reversed. Electrophoresis showed an increase in all globulin fractions, especially alpha-2. Urine analysis was negative. 